observations purporting to refer to that planet have been made, at seven oppositions. When these are submitted to rigorous treatment and the perturbations carefully computed, it is found that the observations in $1875,1879,1886$, and I 887 can be represented with satisfactory accuracy, but the observations of I88 I, I 885, and I894 cannot be satisfied with the same elements. While the normal places formed from the first-mentioned four years have only nominal errors, those in the other years present the following deviations :-

\begin{tabular}{|c|c|c|c|c|}
\hline & & $d \alpha=+25.29$ & & $d \delta=-219 \cdot 1$ \\
\hline & $\cdots$ & $",=+38 \cdot 20$ & $\cdots$ &,$=-2 \quad 0.8$ \\
\hline & ... & $y=+30.48$ & .. &,$=-355^{\circ} 3$ \\
\hline
\end{tabular}

The obvious explanation that some numerical error in the calculations has led to this unusual result is excluded by the detail that Lieut.-Col. von Groeben has given in his description of the processes employed (Ast. Nach., No. 3372). To suggest that another small planet exists moving in a similar orbit, and at present in a very similar position in that orbit, is likely to meet with opposition. The difficulty remains, however, unexplained. The similarity of the deviations from the computed path of Abundantia, both in amount and in direction, is a suspicious circumstance which, however, does not offer a definite clue. Future observation must be looked to for the explanation of the enigma, and von Groeben furnishes an ephemeris for 1896 November, which may induce observation and supply the solution of the riddle. Photographs of the district seem to offer the most likely solution, since the existence of the hypothetical planet, probably of equal brilliancy with Abundantia, should declare itself on the photographic film at no greater distance from the real or known planet than is shown by the errors above.

Cycies of Solan Eclipses.-In the Bulletin de la Soc. Ast. de France for July I896, p. 248 , M. C. Flammarion gives the history of the recent eclipse as an example of the well-known period of I 8 years I I days, the Saros, and in the course of the paper several new points are elucidated. Thus in considering any set of solar eclipses, the constants of each are found to vary regularly according to the position in the cycle. Taking the place on the central line where an eclipse begins, the next eclipse in the cycle, after an interval of I8 years I I ! days, will hegin at a place about I I $8^{\circ}$ west longitude, while another similar period will cause the third eclipse to begin in very nearly the same longitude as the first one. When plotted on a globe, the traces of the consecutive shadows appear curiously regular in the form of a triangle round the pole.

In latitude each eclipse begins a little north of its predecessor; the difference is about $8^{\circ}$ for the beginning of eclipse, $4^{\circ}$ for the middle, and $2^{\circ}$ for the end. Continuing, it is found that the fourth eclipse has a path almost parallel to the first, but much to the north. It thus appears that in a given region a solar eclipse will recur after an interval of three ordinary cycles, each of 18 years $1 \mathrm{I} \frac{1}{2}$ days.

This secondary period of fifty-four years comprising three metonic cycles, M. Flammarion thinks has been unnoticed, and the remarks that it may prove more useful than the smaller period, or Saros, in predicting solar eclipses. There appears to be a regular march of the line of totality from the south to the north pole, the time taken being ten of the long cycles, or about 540 years.

Stars having Peculiar Spectra.-Prof. E. C. Pickering, in Ast. Nach., 3370, gives details concerning the spectra and positions of eighteen stars which have been found by Mrs. Fleming to possess peculiar spectra, giving suspicion of variability. Seven of these are set down as being of Type IV., but three only are of the normal type, the remaining four containing lines of shorter wave-length. New evidence has been obtained regarding two objects previously announced as having peculiar spectra, in Ast. Nach., vol. cxxxv. p. I95, and they are now shown to belong to a different type to that formerly given. One of these, whose position for 1900 is R.A. = 17h. $38^{\cdot 25}$., Decl. $=-46^{\circ} 3^{\prime}$, was thought to be a stellar object having the spectrum of a gaseous nebula, but now proves to have a faint continuous spectrum, together with bright hydrogen lines, $\mathrm{H}_{\beta}, \mathrm{H}_{\gamma} . \mathrm{H}_{\delta}$, $\mathrm{H}_{\varepsilon} . \mathrm{H}_{\zeta}$. The bright nebular line at 5007 is absent, so that this body more nearly resembles $\eta$ Carinæ. The second object has the position R.A. $=$ I $8 \mathrm{~h} .39^{\circ} 3 \mathrm{~m} .$, Decl. $=-33^{\circ} \mathbf{2 7 ^ { \prime }}$; formerly announced as being of Type V., it now proves to have the spectrum of a gaseous nebula.

NO. I 400, VOL. 54$]$
Comet Brooks ( 1889 V.), I 896.- The accuracy of the revised ephemeris of J. Bauschinger, noted in Nature, August I3, has been confirmed by an observation of the comet made by $\mathrm{H}$. Kobold, at Strasburg Observatory, on August I I (Ast. Nach., 3372 , p. 206). He describes the comet as being feeble, and about 0.5 of arc in diameter; in form round, with a small central condensation: The observation is considered fairly trustworthy. As the corrections the observer gives for reducing the positions stated in the ephemeris to those actually observed are only -0.49 s. and $-0.7^{\prime \prime}$ in R.A. and Decl. respectively, the ephemeris will need no alteration for purposes of continued search.

\section{CONTRIBUTIONS TO THE ANTHROPOLOGY} OF BRITISH INDIA.

$M R$. EDGAR THURSTON, the energetic Superintendent of the Madras Government Museum, has recently turned his attention from zoology to anthropology, and in his fourth Bulletin has published the first of what we hope will be a series of investigations on the ethnography of the Madras Presidency. Thanks to the example set by Mr. Risley, the reproach of lack of interest in the natives of India on the part of residents is now being removed, and we hope that Mr. Thurston and others will continue this extremely important line of study. The title of the memoir is "Anthropology of the Todas and Kotas of the Nilgiri Hills; and of the Brahmans, Kammalans, Pallis, and Pariahs of Madras City." A large number of measurements are published, and the paper is illustrated with twenty-one plates, many of which are excellent.

One-half of the Bulletin deals with that very interesting autocthonous people, the Todas, who are nearly as hairy as the Ainu, and who likewise exhibit affinities with the Australians, although their high, straight nose, and fairly regular features, give them a more pleasing appearance than the latter. The typical Toda man is above medium height ( $5 \mathrm{ft} .6 \frac{3}{4} \mathrm{in}$.), well-proportioned, and stalwart; he is dolichocephalic $(73 \cdot 3)$, with projecting superciliary ridges. A valuable account is given of the customs and religion of these herdsmen, which supplements previously pub. lished descriptions. Morality is reduced to a very low ebb before marriage, and truthfulness is not held in great regard. The Todas are endogamous as a tribe, and even as regards some of the five clans, intermarriage between the Paiki and Pekkan clans is said to be forbidden. The buffalo sacrifice is their only purely religious ceremony; it is supposed to bring good luck, and make the buffaloes yield abundant milk. A buffalo calf is killed by a blow on the head from a piece of sacred wood; the assembled Toda men (women are not permitted to take part in the ceremony) salute the dead animal by placing their foreheads on its head. According to Breeks, the flesh must be roasted on a fire made by rubbing two sticks together, and eaten by the celebrants. That is, the divine animal is periodically killed without shedding its blood, the flesh is not sodden by boiling, and the communicants eat their divinity for the benefit of the community : save on these occasions the Todas never eat meat. Mr. Thurston, however, was informed that the flesh is given to the Kotas.

The Kotas, who are allied to the Todas, are excellent artisans, being especially skilled as blacksmiths-they also pursue agricul. ture; but they are universally looked down on as being unclean feeders and carrion-eaters. Their diet evidently agrees with them, as they are a hard, sturdy set of men. Several of their customs are detailed. The Todas are slightly taller $(1696 \mathrm{~mm}$.) than the Kotas $(1629 \mathrm{~mm}$.), but they have the same weight (I 5 lbs.). They are also broader shouldered, and, though they do less manual work, their hand-grip is considerably greater. The cephalic measurements in both average about the same (length, $19^{\circ} 2 \mathrm{~mm}$. ; breadth, $14.2 \mathrm{~mm}$. ; index, 74).

The short account of the measurements of forty men of each of the four Bengal castes is suggestive. It is evident that the Brahmans are here a mixed Aryan and Dravidian people ; below these are the Kammalans, or artisans ; still lower are the Pallis, or agriculturists; and the lowest are the Pariahs ; but there are traces that these once held a higher position. Risley found the nasal index coincided to a remarkable extent with the caste rank. And here we find the same story; for these four castes it is, respectively, $76.7,773,77^{\circ} 9$, and 80 ; but the Pariahs are eclipsed by the Paniyans $\left(95^{\circ} \mathrm{I}\right)$, about whom Mr. Thurston promises us further information. There is very little difference in height between the Brahmans $(1625 \mathrm{~mm}$.) and the Pariahs 
(I62: mm.), but the Kammalans are shorter (I $597 \mathrm{~mm}$.). The Brahmans are better nourished, and have broader heads (I42 $\mathrm{mm}$.), the other three castes averaging I $37 \mathrm{~mm}$. ; they also have the largest hands. Taking them all round, there is not that difference between the Brahmans and Pariahs that one might expect to find; but this can be explained by racial mixture.

$$
\text { A. C. } \mathrm{H} \text {. }
$$

\section{SCIENTIFIC EDUCATION IN GERMANY AND ENGLAND. ${ }^{1}$}

IN our frequent discussions on scientific education, we have both often been struck with some points of very great difference between the English and the German way of dealing with it. As it may be asserted without national arrogance that University education is in Germany in a more satisfactory condition than in your country, you are, of course, anxious to know which of the German customs I consider most effective in bringing about this better state of things; and I will, therefore, try to point them out. Of course, I shall confine myself to the subject of natural science, and especially chemistry and physics, feeling myself unable to deal with sciences beyond my knowledge. The main point of our system may be expressed in one word-freedom-freedom of teaching and freedom of learning. The first involves for the teacher the necessity of forming in his mind a clear conception of the scope of his science, for, as he is free to choose any possible method of view, he feels himself answerable for the particular one he has chosen. And in the same way the student feels himself responsible for the method and the subjects of his studies, inasmuch as he is free to choose any teacher and any subject. One who has not seen this system in action may be inclined to think that such a system must lead to arbitrary and irresponsible methods on the side of the teacher, and to confusion on the part of the student. But the former is avoided, because at the beginning of his career the teacher is dependent for his advancement on the results of his scientific views, and is naturally anxious to improve his position in the educational world. And as for the students, they themselve impose certain restrictions on their own freedom. Most of them feel that they require some advice and guidance, and they therefore follow the usual and approved order in conducting their studies. As to the inventive man of original ideas, it has often been proved that for him any way is almost as good as any other, for he is sure to do his best anywhere. Moreover, such a man very soon excites the interest of one of his teachers, and is personally led by him, generally to the great advantage of both.

Let me illustrate these general remarks by considering the course followed by an average chemist. In his first half-year he hears lectures on inorganic chemistry, physics, mineralogy, sometimes botany, and of late often differential calculus. Moreover, the German student is accustomed to take a more or less strong interest in general philosophy or history, and to add in his Belegbuch (list of lectures) to the above-named Fachcollegien (specialised studies) one or two lectures on philosophy, general or German history, or the like. Very often there are in the University one or more popular professors whose lectures are heard by students of all faculties without reference to their special studies. The student who has heard during his stay at the University only lectures belonging strictly to his Fach, is not well thought of, and is to some extent looked down on as a narrow specialist. But I must add that such views are not prevalent in all faculties, and there are some-e.g., the faculty of law-whose students confine themselves, with few exceptions, to attending exclusively lectures in that faculty.

In the second half-year the chemical student begins with practical laboratory work. Notwithstanding the perfect freedom of the teachers, the system first introduced by Liebig into his laboratory at Giessen is still universally adopted in German universities and technical high schools-viz. qualitative and quantitative chemical analysis, the former conjoined with simple spectroscopic work, the latter amplified by volumetric analysis. This is followed by a course of chemical preparations, formerly chiefly inorganic, now chiefly organic. Even here, a regular system is being widely developed owing to. the use of some well-known text-books. Of late years this course is

1 A letter from Prof. W. Ostwald, communicated by Prof. W. Ramsay to the Times, August 25.

NO. I 400, VOL. 54] followed in some laboratories by a series of exercises in physical chemistry and electro-chemistry.

While these practical exercises, which last for three or four half-years, are being carried out, the student completes his knowledge of physics, mathematics, and the other allied sciences by hearing lectures and working practically in the physical and often also in some other laboratory. The exercises done, he goes to the professor and asks him for a "theme" to begin his "work" - viz., his dissertation for the degree of Doctor of Philosophy. This is the most important moment in his life as a student, for it generally determines the special line of his future career. The "theme" is usually taken from the particular branch of the subject at which the professor himself is working; but, as the scientific name and position of the professor depends, not only on his own work, but to a large extent on the work issuing from his laboratory, he is careful not to limit himself to too narrow a range of his science.

Of course it is best of all if the student selects for himself a suitable "theme," suggested to him by his lectures or practical work, or from private study of the literature of the science. But this seldom happens, for the young student is not yet able to discern the bearing of special questions, and lacks knowledge how to work them out. Sometimes (but not very often, indeed) he points out to his professor in a general way the kind of problems he would like to work at, and the professor suggests to him a special problem out of this range of subjects. During the working out of his chosen subiect the student learns generally much more than he has heard at lectures. Every part of the investigation forces him to revise the scientific foundations of the operations he performs. During this time the incidental short lectures given by the professor on his daily round from one to another of the advanced students are most effective in deepening and strengthening the student's knowledge. As these explanatory remarks are generally heard not only by the student whose work has caused them, but also by a number of fellow-students working near, a fairly wide range of scientific questions are dealt with in their hearing. Often these small lectures develop themselves into discussions, and, as for myself, I judge from the frequency of such discussions between the students whether the session will turn out a good one or not. If the professor thinks the work sufficiently complete to be used as a dissertation, the student proceeds to the close of his studies. He prepares himself for the examination, which is conducted by the very professors whose lectures he has heard and in whose laboratories he has worked. This examination varies somewhat in different universities, but in no case is it either very long or extensive indeed, it is not considered as very important. For we are all aware what an uncertain means of determining a man's knowledge and capabilities an examination is, and how much its issue depends upon accidental circumstances. Part of this uncertainty is removed by the fact that the professor and the pupil know each other, are acquainted with one another's modes of expression and scientific views. The main purpose of the examination is to induce the student to widen his knowledge to a greater extent than is covered by the subject of his dissertation; but, indeed, it happens very seldom that a student whose work is considered sufficient does not pass the examination.

We have no great fear that this system may induce a professor to treat his own pupils in too lenient a way, and so lower the standard of the Doctor's degree. There was a time when such abuses used to occur, but there very soon arose such public indignation that the abuses ceased to occur. Even at the present day similar instances occasionally occur, but, as before remarked, the position of a professor depends in such a degree upon the value of the dissertations worked out under his supervision, that such deviations from the right way correct themselves in the course of time. The most effective instrument for that purpose is the publication of all dissertations and the consequent public control over them; for this reason publication is, I believe, compulsorily prescribed in all German universities.

When the student has finished his course he is still entirely free to choose between a scientific and a technical career. This is a very important point in our educational system ; it is made possible by the circumstance that the occupation of a technical chemist in works is very often almost as scientific in its character as in a university laboratory. This is connected with a remarkable feature in the development of technical chemistry in Germany - the very point upon which the important position of chemical manufacture in this country depends. The organisation of the power of invention in manufactures and on a large 